\title{
Post-disaster Tribe Relocated Reconstruction and Sustainable Development of Ulaljuc Village
}

\author{
Hsiao-Ming Chang ${ }^{1}$, Chin-Lung $\mathrm{Chou}^{2}$ and Cheng-Lung $\mathrm{Wu}^{3 *}$ \\ ${ }^{1}$ School of Physical Education, Putian University, China \\ ${ }^{2}$ Department of Tourism Leisure and Health, Chungyu Institute of Technology, Taiwan \\ ${ }^{3}$ Department of Marine Sports and Recreation, National Penghu University, Taiwan
}

\begin{abstract}
Ulaljuc Village is an indigenous tribe that was relocated and reconstructed due to a disaster, and mainly developed by the coffee industry for post-disaster industrial recovery. This study chose Ulaljuc Village as the research target, and collected data using various research methods, such as participant observation and in-depth interviews. The analysis results show that: (1) with assistance from government public sectors and non-profit organizations, and respect for the planning of indigenous peoples, the tribe was able to implement relocation reconstruction; (2) the development of the coffee industry enabled the tribesmen to gain economic profits and maintain the coffee plantation to effectively support the livelihood of tribesmen. Hopefully, the case in this study can serve as reference for the future industrial development of tribes or communities implementing post-disaster reconstruction.
\end{abstract}

\section{Introduction}

In recent years, climate change has become an important issue of international concern. Natural disasters cause severe damage and shock to human life, as well as subsequent social-related issues, which are faced by all nations [1]. Large-scale destructive natural disasters cause a large amount of financial and non-financial damages to countries and communities, change the residents' original lifestyle and environment, and may even cause psychological and cognitive trauma to the victims [2]. As some post-disaster areas are no longer habitable for human beings, there is a need to implement relocation reconstruction, and residents have to adapt to the reconstructed communities. Although communities implementing relocation reconstruction aim to recover a similar lifestyle, post-disaster communities implementing reconstruction have to face a lot of challenges, including buildings, public facilities, environment, culture, streets, and residents' residence allocation from scratch. After the formation of community structures, the maintenance of livelihood is an issue to be faced by victims [3]. On August 8, 2009, Typhoon Morakot ravaged southern Taiwan and caused an unprecedented disaster. Taiwu Village of Taiwu Township, Pintung County, which was located in the western Mt. Kavulungan area, suffered from landslides and cracked houses due to heavy rain. According to expert evaluation, the tribe site was extremely dangerous and no longer habitable, and the tribe had to be relocated from the disaster area, where the reconstruction process involved residents' adaptation and the issue of industrial development. Therefore, the main purpose of this study is to analyze how the Paiwan tribesmen reconstructed their culture and combined the coffee industry with local tourism resources to maintain the livelihood of tribesmen after leaving the original tribe and implementing relocation reconstruction. Hopefully, the analysis results of this study may serve as reference for indigenous tribes and communities implementing post-disaster reconstruction in other countries and regions.

\section{Reconstruction of Ulaljuc Village}

The basic principles are "staying away from disasters, but not breaking up a village; leaving a village, but not leaving a township; keeping the new village close to the original township, as much as possible." With the efforts of Taiwan's governmental departments, experts, and the Paiwan tribesmen of Taiwu Village, after 6 months of seeking the best place for relocation at 6 locations, the tribesmen eventually chose a location closest to the original township - Wanluan Township, Chishan Section of Taiwan Sugar Corp. as the permanent tribal base. The Reconstruction Council of the Executive Yuan asked for help from the Red Cross Society of the Taiwan to support the reconstruction, and integrated the resources of various government departments to implement the overall planning of the tribe. On July 10, 2010, the foundation was laid using the cornerstones moved from the Old Taiwu Tribe. During stage 1 of the reconstruction, a total of 117 permanent houses, 1 activity center, 1 coffee industry hall, and 1 school were built. During stage 2 of the reconstruction, the construction of 40 permanent houses was completed on August 15, 2011, and the tribesmen settled down to turn these permanent houses into homes. 
Moreover, the tribe held a meeting and agreed to rename the tribe as "Ulaljuc Village" (Taiwu Township in Paiwan language). The tribe's reconstruction and development can be explained from two aspects, cultural reconstruction and industrial development, as follows:

\subsection{Cultural Reconstruction}

The Paiwan Tribe originated from Mt. Kavulungan in Taiwan [4]. The legend has it that the Sun laid two eggs in

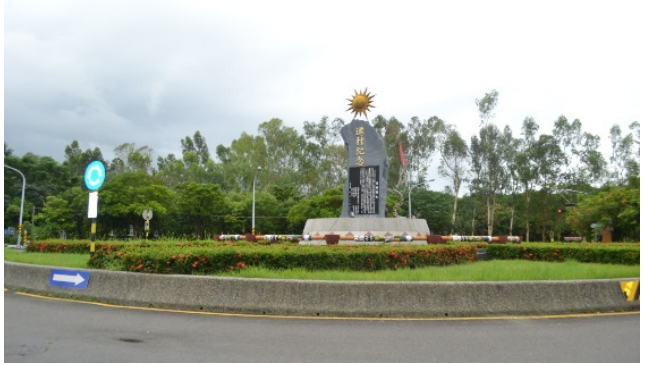

Fig1. Monument for Tribal Relocation
As the Paiwan Tribe is a tribe with distinct classes, a tribesman's class is determined when he/she is born. There are a total of 4 classes, including chief, nobles, warriors, and civilians [5]. The chief is hereditary, and the chief owns land, hunting areas, and rivers. The civilians are tenant farmers, who have to rent land from their chief for farming, and pay tribute to the chief during harvest season. The chief title is inherited by the eldest son, and the remaining siblings are nobles. Classes above the aristocracy are entitled to gorgeous costumes and lintel carvings. The warrior class consists of civilian families with special merits or talents, and are respected in the tribe, such as engravers and hunters. Therefore, in the tribe, the chief's house is very important. In particular, the "stone

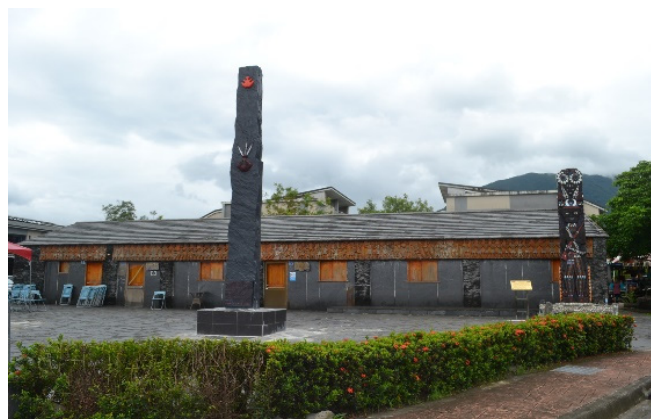

Fig3. Traditional Stone House of the Chief and Stone Pillar

Although modern European style modular houses were constructed for the tribe, the cultural traces of the Paiwan Tribe can be seen everywhere; for example, Taiwu Elementary School (see Figure 4) is a place for formal education and one of the centers of the cultural heritage of the Paiwan Tribe. The campus is filled with indigenous totems and billboards explaining the life development and ethnic history of the tribe. a clay pot in a white stone house on the hilltop, and the two eggs hatched into a boy and a girl, who are the origins of the Paiwan Tribe. Although the legend seems to be absurd, the Paiwan Tribe never forgets its origins. After the tribal relocation following the typhoon disaster, the Sun was placed on the top of a monument erected in the relocated tribe, and the monument was decorated with Paiwan glass beads (see Figure 1). At the entrance of the tribal village, a statue of a male warrior preparing to go hunting and a solemn facial expression wears the traditional clothing of the Paiwan Tribe (see Figure 2).

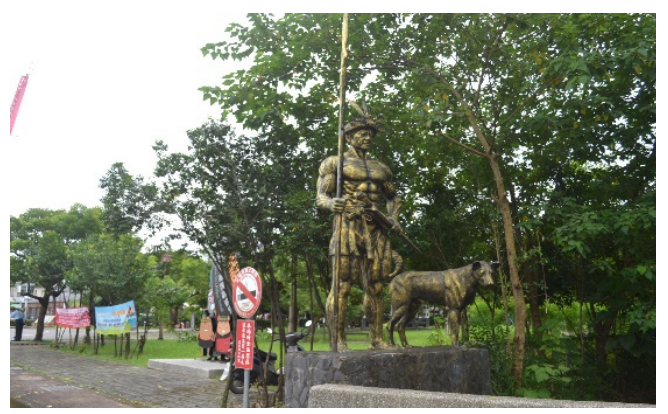

Fig2. Warrior Statue of Paiwan Tribe

pillar" in front of the chief's house represents "the one and only" and the "dominant standing' symbol. The stone pillar and the chief's house in Figure 3 are imitated from those in front of the Arangiyan's house in the Old Taiwu Village. In addition to representing the distinguished status of the chief, they unite the tribesmen, represent their unity, harmony, honor, and are the symbol of cultural heritage. In order to preserve and pass down the existing traditional cultural of Ulaljuc Village, subsidies are offered for the relocation construction of the tribe. This tribe is the first tribe to possess a permanent foundation of a stone house cultural hall that extends and passes down the traditional culture of indigenous peoples.

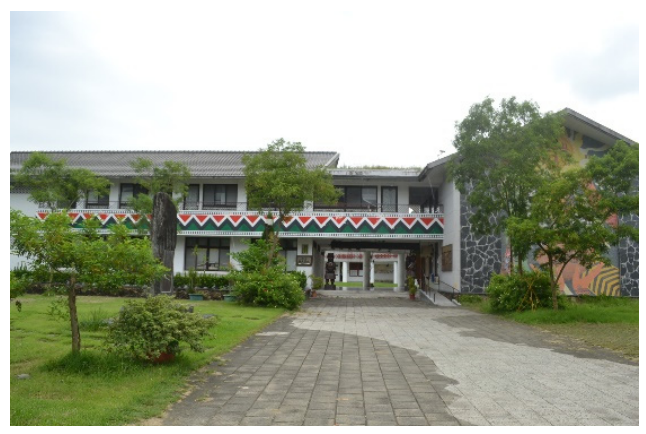

Fig4. Campus Scenery of Taiwu Elementary School

\subsection{Industrial Development}

During WWII, the command center of the Japanese army "Mt. Kavulungan Guards" was located about $5 \mathrm{~km}$ outside Taiwu Village. The commander returned to Japan after Japan surrendered, and revisited Taiwu Village in 1961. At that time, he sent 200 Arabica coffee saplings to old 
friends Guo and Tseng, thus, the coffee trees were spread in the Taiwu area. Later, after the Japanese left Taiwan, and tribesmen did not understand the use and making method of coffee, and the coffee trees were cut or left to waste. In 2003, Yulin Guken held the "Taiwan Coffee Festival" to teach everyone to about Taiwan's coffee. The tribal priest introduced the method of growing coffee beans, and some villagers began to invest in coffee cultivation. However, due to the attack of Typhoon Morakot, the village was no longer habitable, and the

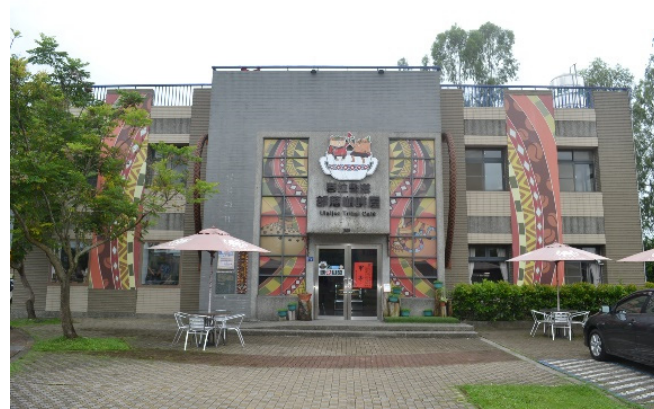

Fig5. Ulaljuc Tribe Coffee House

\section{Discussion}

\subsection{Cultural Reconstruction of Indigenous Peoples}

For indigenous peoples, leaving their hometown is a difficult decision, as they must abandon the land of their ancestral spirit. After this typhoon disaster, the government departments in Taiwan spent a lot of time communicating and coordinating with the indigenous peoples to eventually reach a consensus; however, as safety was prioritized, the final decision failed to consider the principle of "staying away from disasters, but not breaking up a village", as originally proposed by the government. While the indigenous peoples who originally lived in Taiwu Village were willing to cooperate with the policy of village relocation, after the village was relocated, the living environment was very different from the original tribe (the tribe was converted into a community with European buildings), and the tribesmen suffered from post-disaster trauma, as they had to face the issues of poor adaptation to the new environment and the loss cultural identity [7-8]. Traditionally, the chief of the Paiwan Tribe is responsible for managing land, where the tribesmen pass down the ecological knowledge, social norms, and cultural traditions of the land to develop a social organization similar to a country. Traditional tribes are a geographical group composed of many families, and the chief was the leading center of the tribe who united and protected the homes of civilians. The status of the chief is no longer important in modern society, and the chief has been replaced by other people with political powers (e.g. public representatives and regional magistrates). However, during the reconstruction, the chief and the cultural traditional and system of Paiwan Tribe united the coffee industry in Taiwu faced the issue of survival. Fortunately, Dr. Wei-jie Hua, who is the offspring of the chief's family in Paiwan Tribe, honored the ancestral spirit by using the name of the tribe "Ulaljuc," and created the indigenous peoples' coffee brand "Kavulungan," which established a cooperative club to cultivate talents in the coffee industry (see Figure 5). Afterwards, the coffee industry hall was established in the tribe (see Figure 6) to promote the selling of Taiwu coffee [6].

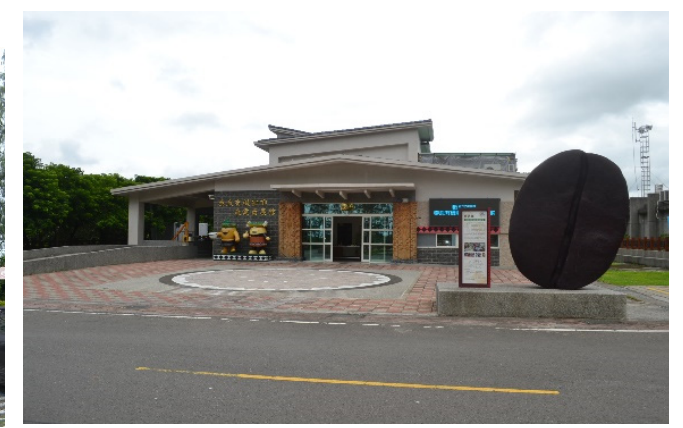

Fig6. Taiwu Organic Coffee Industry

Development Hall

tribesmen, and assisted them in adapting to the new environment to appease their pain and sorrow, which contributed a lot to the tribe. The "Ulaljuc Cultural Hall meaning the Arangiyan Chief's House" in the tribe, is not only a representative building with architectural features of indigenous peoples, it was also being built according to the tribe's tradition. The decorations and space planning in the house are consistent with the lifestyle of a traditional chief, and consider the features of cultural heritage, which enabled the tribesmen in Ulaljuc Village to regain its history and cultural memories. Moreover, the buildings, school, and streets in the tribe are decorated with the totems and traditional culture and colors of the Paiwan Tribe, which also enabled the tribesmen to understand their own cultural origins and develop their ethnic and cultural identity. The newly built Taiwu Elementary School is worthy of mentioning; in addition to serving as the location for normal education, it is one of the centers of cultural heritage of the Paiwan Tribe. Therefore, the experts of the Civil Engineering Society in Japan call it "the most beautiful elementary school in the world."

\subsection{Industrial Development}

Another important issue for post-disaster relocation reconstruction is residents' livelihood. Before the typhoon disaster, because the original tribe was located in the mountains, it was seldom visited by tourists due to inconvenient traffic, thus, the coffee sales channels were also limited. Although village relocation took the Paiwan tribesmen in Ulaljuc Village away from their ancestral hometown, it improved accessibility because the geographical location of the community is closer to Pingtung City. As there is a well-known scenic spot, meaning the Catholic Church of Wanchin, in the proximity of the relocated tribe, tourists visit the tribe before visiting the church, which is beneficial to the 
development of both the coffee and tourism industries. Moreover, there is a more important factor - the changes in the lifestyle and eating habits of residents in Taiwan. Drinking coffee has become a part of daily life and a leisure lifestyle. Due to the efforts and assistance of Dr. $\mathrm{Ha}$, the establishment of a cooperative club has played an important role from coffee planting and roasting to marketing, which has helped cultivate talents in the industry. Moreover, the establishment of the tribe's coffee industry hall, the introduction of new technologies, and the procurement of machines with subsidies from the government have helped attract more villagers to engage in the coffee industry, which enables the tribesmen to gain income. However, the coffee trees are still planted in the original tribe location on Mt. Kavulungan, thus, the elderly members of the tribe engage in planting on the mountain during weekdays, and on holidays, the tribesmen harvest coffee beans to produce coffee. In order to effectively sell coffee, the coffee brand "Kavulungan", as created by the tribe, is the first indigenous coffee brand introduced to department stores. Furthermore, this brand won $3^{\text {rd }}$ place in the special ranking of the Asia-Pacific area in 2016 in the accreditation competition held by an internationally famous coffee magazine. The coffee quality in Pingtung has been compared with world brands. The tribe also established a biotechnology company specializing in the R\&D of relevant products derived from coffee grounds, coffee fruit peels, coffee leaves, etc. In addition to selling coffee, the tribe provides tourists with coffee bean roasting activities, viewing the chief's house, coffee bean roasting DIY, and sharing the cultural experiences of the Paiwan Tribe.

\section{Conclusion and Suggestions}

\subsection{Conclusion}

The research results show that, after the typhoon disaster, the government departments integrated non-profit organizations and public welfare organizations to assist in the tribe's reconstruction, which was the most important factor. During the reconstruction of Ulaljuc Village, although it was impossible to follow the principle of "staying away from disasters, but not breaking up a village," the relationship between the tribesmen and the "land" was taken into account, which enabled the tribesmen to reach the site of ancestral spirit in a convenient manner. In addition, the traditional culture of the tribe plays the critical role in uniting the tribesmen. This study found that the existing social system of the Paiwan Tribe, as well as the cultural totems and symbols of tradition, have a positive effect on the tribe's reconstruction. In terms of industrial development, with the efforts made by both the government and the tribesmen, the coffee trees that were originally planted by the tribe were utilized to create economic income for the tribesmen, which attracted the youth to return to the tribe for work. In addition, the tribesmen also frequently return to the original site of the tribe when planting and harvesting coffee beans, which enables them to mentally resonate with their ancestors' hometown and prevents them from perceiving the sense of loss caused by village relocation.

\subsection{Suggestions}

The economic developments in indigenous peoples' townships are usually disadvantaged due to inconvenient traffic. Hopefully, the industrial operation and development model of this study case with regional characteristics, which combine regional culture, environment, scenery, and residents with consumerproducer regional collaboration, may serve as reference. This study was conducted approximately 10 years after Ulaljuc village relocation, as explanations about relocation reconstruction in the past are insufficient to meet current needs. Future studies are advised to perform more in-depth interviews regarding how the tribe reached the consensus of coffee industry development within this decade, as well as how the tribesmen engage in the model of the joint operations of the coffee industry.

\section{Acknowledgments}

This study was supported by a grant from National Social Science Foundation of China (No.18BMZ130).

\section{References}

1. Xu, J., Wang, Z., Shen, F., Ouyang, C., Tu, Y. (2016). Natural disasters and social conflict: A systematic literature review. Int. J. of Disaster Risk Reduction, 17: 38-48.

2. Benight, C. C., Ironson, G., Klebe, K., Carver, C. S., Wynings, C., Burnett, K., Schneiderman, N. (1999). Conservation of resources and coping self-efficacy predicting distress following a natural disaster: A causal model analysis where the environment meets the mind. Anxiety, Stress \& Coping: An Int. J, 12(2) 107-126.

3. Tarlow, P., Korstanje, M. E. (2013). Disasters, tourism and mobility, the case of Japan earthquake. Pasos. Revista de Turismoy Patrimonio Cultura, 11(3): 732.

4. Pasaljaig, Tjangkus., Chen, Shu-Mei. (2015). Paiwan's cultural space and land attachment in Taiwan. Journal of the Taiwan Indigenous Studies Association, 5(2): 115-135.

5. Council of Indigenous Peoples (2020). Paiwan peoples. https://www.apc.gov.tw/portal/doc List. html?CID= B68 D98A9742D94C7

6. Ku, Wen-Hua., Yung, Ing-Shan., Tang, Hsiu-Li. (2016). Established the co-creating unique value business model with the acrossing organizational capacities of the local characteristics industry- A case study of the Pingtung County Taiwu Coffee. JLRIM. 9(2): 49-78.

7. Cernea, M.M., (1996) Understanding and preventing impoverishment from displacement. In the McDowell, C. (Ed), Understanding impoverishment: the 
consequences of development induced displacement. Berghahn Books, Oxford. pp.13-32.

8. Sussman, N. M. (2002). Testing the cultural identity model of the cultural transition cycle: Sojourners return home. Int J. of Intercult R, 26(4): 391-408. 